\title{
GLOSSARY OF INDONESIAN AND DUTCH TERMS
}

$\begin{array}{ll}\text { Adat } & \text { Tradition, customary law } \\ \text { Afdeeling } & \text { Dutch colonial administrative division } \\ \text { Alang } & \text { Rice barn } \\ \text { Aluk } & \text { Ritual, symbolic action, religion; also defines animist } \\ & \text { in contrast to Christian or Muslim } \\ \text { Ambe' } & \text { Father; village or group head } \\ \text { Arisan } & \text { Rotating savings and credit funds } \\ \text { Badan } & \text { Body or committee } \\ \text { Bahasa Indonesia } & \text { Indonesian language } \\ \text { Ballo' } & \text { Palm wine } \\ \text { Banua } & \text { House } \\ \text { Bua' } & \text { A ritual community that celebrates together a kind of } \\ & \text { agricultural new year with the aim of imploring the } \\ & \text { higher powers to smile on man, beast and the pro- } \\ \text { Borongna } & \text { duce of the fields } \\ \text { Bupati } & \text { Section or sharing group } \\ \text { Camat } & \text { District head } \\ \text { Complex } & \text { Head of the kecamatan; subdistrict head } \\ \text { Controleur } & \text { Dutch colonial administrative subdistrict } \\ \text { Damar } & \text { Dutch administrator on a district level } \\ \text { Dapo' } & \text { Resin } \\ \text { Desa } & \text { Kitchen, hearth } \\ \text { Dusun } & \text { Village } \\ \text { Gengsi } & \text { Hamlet } \\ \text { Gotong Royong } & \text { Prestige } \\ \text { Ikatan (Ind.) } & \text { Mutual cooperation } \\ \text { Indo' } & \text { Literally a bundle, but it is better understood as a tie } \\ \text { Jaman Belanda } & \text { that binds, or even better as a union } \\ \text { Kabupaten } & \text { Mother } \\ \text { Kampung } & \text { Dutch Era } \\ \text { Karopi' } & \text { District } \\ & \text { Hamlet } \\ \text { Kaunan } & \text { Federations of tongkonan that celebrate particular } \\ & \text { rice ceremonies together } \\ \text { Slave }\end{array}$


Kebun

Kecamatan

Keluarga

Kepala

kepala daerah

Kerukunan

Kombongan

Kotamadya

Landstreek

Layuk

Lelang

Lembang

Liang

Lingkungan

Ma'bua

Mana'

Maro

Ma'siri'

Merantau

$N e^{\prime}$

Nene'

Onderafdeling

Oom

Padang

Padi

Paniuran

Penanian

Pete pete

Potoktengan

Puang

Rantau

Rante

Rambu tuka'

Rambu solo'

Rapu
Garden (usually for the cultivation of perennials like coffee, cocoa, etc.)

Subdistrict

Family

Head

district head

Association

Committee; meeting

Municipality

Colonial Dutch administrative subdistrict

Old (in combination with tongkonan referring to the oldest)

Meat division

Literally vessel; district; adat community

Family tomb

Urban administrative unit

Highest smoke-rising ritual

Heirlooms

Smoke-rising ritual; literally crazy

Ashamed

To go abroad

Respectful title

Grandparent; ancestor

Dutch colonial administrative subdivision

Uncle

Land

Rice, paddy

Obligation to contribute; ritual debt

Federations of tongkonan that celebrate particular rice ceremonies together

Minibus

Twelve nobles

Owner; master (of a slave); highest-ranking nobility in southern Toraja

Literally; coast or outer area

Ceremonial field

Smoke-rising

Smoke-descending

Family 


$\begin{array}{ll}\begin{array}{l}\text { Rarabuku } \\ \text { Reformasi }\end{array} & \text { Family; literally 'blood bones' } \\ \text { Rombongan } & \text { Political reform } \\ \text { Rupiah }(R p) & \text { Formal guest procession at a funeral } \\ & \begin{array}{l}\text { Indonesian currency unit. Between } 2001 \text { and } 2005 \text { the } \\ \text { rupiah rate of exchange with the US dollar fluctuated } \\ \text { between 10 and 12,ooo }\end{array} \\ \text { Saroan } & \text { Meat-sharing and labour group } \\ \text { Saung } & \text { Cockfighting } \\ \text { Sawah } & \text { Wet ricefield } \\ \text { Sipasang } & \text { Pair } \\ \text { Siri' } & \text { Honour/shame } \\ \text { Sugi' } & \text { Rich } \\ \text { Sumanga' } & \text { Life-energy } \\ \text { Tallu } & \text { Three } \\ \text { Tana' } & \text { Hereditary status, a tethering stake } \\ \text { Tante } & \text { Aunt } \\ \text { Tau tau } & \text { Effigy of the deceased } \\ \text { Tegal } & \text { Dry land } \\ \text { Tepona } & \text { Four } \\ \text { To } & \text { Person } \\ \text { To'makaka } & \text { High noble } \\ \text { To minaa } & \text { Ritual specialist, priest of the right; literally 'the one } \\ \text { To'Parenge } & \text { who knows' } \\ & \text { A rank of important people used in north Toraja, } \\ \text { often associated with ritual leader of a karopi' } & \text { (village) } \\ \text { To' } & \text { Place; clustered strands } \\ \text { Tondok } & \text { Community, settlement } \\ \text { Tongkonan } & \text { Ancestral house } \\ \text { Tuak } & \text { Palm wine } \\ & \end{array}$

